\title{
Política social e ajuste macroeconômico
}

\author{
Social policy and macroeconomic adjustment
}

Nilson do Rosário Costa 1

\footnotetext{
1 Departamento de Ciências Sociais, Escola Nacional de Saúde Pública, Fundação Oswaldo Cruz. Rua Leopoldo Bulhões 1480, Rio de Janeiro, $R J$ 21041-210, Brasil. nilson@ensp.fiocruz.br
}

\begin{abstract}
This paper analyzes responses by welfare states to globalization in some OECD countries in the 1980s and 90s, demonstrating that the hypothesis concerning the dismantling of social welfare systems cannot be proven due to lack of evidence of substantial changes in the funding and selection of beneficiaries. The paper also focuses on the effects of internationalization of the Brazilian economy on the country's social protection system. The conclusion is that restrictions imposed on public expenditures severely limited the capacity to promote broad coverage in social policies. During the decade the option was made for targeted, selective social policies based on the adoption of a diagnosis of low effectiveness in the Brazilian social protection system. The case of health policy was an exception, due to capacity for interest mediation in the social arena.
\end{abstract}

Key words Public Policy; Health Policy; Globalization

Resumo O objetivo do texto é fazer um balanço das respostas dos Estados de bem-estar social às mudanças provocadas pelo globalização nas décadas de 1980-1990. O texto mostra que a hipótese sobre o desmantelamento dos sistemas de bem-estar social não pode ser comprovada por falta de evidências de mudanças substanciais nos mecanismos de financiamento e eleição de beneficiários. O texto focaliza também os efeitos do processo de internacionalização da economia brasileira sobre o sistema de proteção social do país. Conclui que as restrições impostas aos gastos públicos limitou severamente a capacidade em promover politicas sociais abrangentes. Verificou-se na década, a opção por políticas sociais focalizadas e seletivas pela adoção do diagnóstico da baixa efetividade do sistema de proteção social brasileiro. O caso da política de saúde foi uma exceção em razão da capacidade de intermediação de interesses na arena setorial.

Palavras-chave Política Social; Política de Saúde; Globalização 


\section{Introdução}

Ao longo das décadas de 1980-1990, tornou-se quase consensual a hipótese sobre o estreitamento das opções de políticas públicas de orientação nacional determinado pelos processos de globalização. Esses processos estariam sustentados pelo ritmo geométrico de crescimento das transações internacionais, com integração de mercados financeiro e comercial, e emergência de novos atores na cena interessados em políticas macroeconômicas de controle dos gastos públicos e focalização dos programas de proteção social.

Para esse diagnóstico, os Estados nacionais estariam mortalmente afetados na sua capacidade de implementação e coordenação política decorrente da crise fiscal em que estavam imersos nos anos 1980. A capacidade de alavancagem e investimento teria se deslocado para as agências de cooperação multilaterais e para o mercado financeiro internacional. Impunha-se assim, a necessidade de estratégias cooperativas e a integração das economias nacionais aos processos de globalização financeira para a captação de poupança externa.

Em decorrência também do fortalecimento das orientações cosmopolitas ou pró-globalização do eleitorado e das elites dirigentes nas novas democracias, as coalizões nacional-desenvolvimentistas teriam também ficado sem margem de escolha para as políticas públicas orientadas para o plano doméstico.

O estreitamento de espaço de manobra para as políticas de desenvolvimento de corte nacional, levaria, quase que necessariamente, à adoção de mudanças nas funções do Estado pela privatização de empresas públicas de infra-estrutura, reforma administrativa com diminuição do funcionalismo público dos governos centrais, corte e seletividade de programas sociais, entre outros itens.

Nas economias centrais, a ameaça do processo de globalização apresentou uma outra feição: foi associada à crise do Estado de bemestar social. A integração ao mercado globalizado, combinada com as mudanças nas economias nacionais, ameaçaram as funções do Estado pela tentativa de reversão das políticas universalistas de proteção social.

Este trabalho faz um balanço sucinto dos efeitos produzidos por esses processos sobre a institucionalidade das políticas sociais na década de 1990, no contexto das economias centrais e no Brasil. A primeira parte do texto destaca a importância das conclusões apresentadas por Pierson $(1995,2000)$, para explicar as saídas para a crise do Estado de bem-estar so- cial nas economias centrais. O foco na discussão das idéias do autor diferencia o texto de uma proposta de revisão exaustiva da literatura sobre a crise do sistema de proteção social nas economias centrais. A segunda parte do trabalho introduz uma discussão ainda mais específica e ausente no debate nacional: a situação da proteção social brasileira na década passada, frente aos processos de ajuste macroeconômico. O propósito da discussão é o reconhecimento das limitações substanciais verificadas nas funções do Estado brasileiro na área social, condicionadas pelas mudanças macroeconômicas da década de 1990.

\section{O debate sobre o desmonte do Estado de bem-estar social da década de 1990}

Pierson (1995, 2000) apresenta argumentos substantivos para rejeitar a hipótese do desmantelamento do Estado de bem-estar social determinado pelas mudanças macroeconômicas conduzidas pela globalização na década de 1990. O autor assinala a diferença entre os sistemas de proteção com benefícios sociais consolidados - como o caso dos Estados de bem-estar social em relação a processos de ampliação da proteção social nas economias secundárias, como o caso brasileiro.

A consolidação dos Estados de bem-estar gerou as condições para a sustentabilidade eleitoral de coalizões social-democratas e socialistas, e a emergência de uma ampla rede de interesses composta por empregados do setor publico, prestadores de serviços e beneficiários.

Nas décadas de 1980 e 1990 essa coalizão enfrentaria, com sucesso, as mudanças brutais na economia globalizada e na capacidade política do "trabalho organizado", neutralizando os ataques conservadores às políticas públicas de natureza redistributiva e às funções do Estado nacional.

Para Pierson, a agenda da reforma do Estado nos anos 90 impunha, em vários casos, perdas tangíveis e concentradas para certos grupos de cidadãos eleitores e prometia benefícios difusos. Não pode demandar apoio eleitoral a nenhum grupo social majoritário no ambiente das democracias consolidadas, a não ser o da comunidade financeira.

A promessa de benefícios difusos e de perdas concentradas recebeu o veto da coalizão de beneficiários do Estado de bem-estar, minimizando ou neutralizando os efeitos das reformas nos anos 1990. Não houve, portanto, o desmantelamento das funções do Estado que tenha afetado $\mathrm{o}$ arranjo original do sistema de proteção social. 
Pierson (2000) apresenta evidências para quatro países (Inglaterra, Alemanha, Suécia e Estados Unidos) de que as transferências para o seguro social mantiveram-se relativamente niveladas entre meados da década de 1970 e 1990.

Os dados para as década de 1980 e 1990 para França, Alemanha, Itália, Suécia, Reino Unido e Estados Unidos mostram também o aumento nas despesas médias nas áreas sociais como proporção do PIB (Tabela 1).

As despesas governamentais e o número de empregados no setor público não sofreram mudanças significativas, exceto na proporção de empregados no governo nos Estados Unidos, em relação ao total de empregados.

Não ocorreu a adoção generalizada de políticas públicas seletivas, baseadas em teste de meio para acesso a benefícios, na transferência de responsabilidade para o setor privado e mudanças nas regras de definição de benefícios. A ampliação desses programas serviria, no limite, como evidência de reforma qualitativa nos mecanismos de elegibilidade, fortalecendo a opção de focalização.

$\mathrm{O}$ autor assinala que algumas políticas públicas estreitaram as regras de elegibilidade ou reduziram os benefícios, principalmente os programas residuais, com baixo desempenho nos países onde a pressão sobre o déficit público foi mais severa. Entretanto, essas reformas foram mais de ajuste dos programas existentes do que a introdução de novos formatos pela focalização seletiva e pela mercantilização das condições de acesso.

A análise de Pierson levou também em conta as dimensões de natureza estrutural - redução da produção industrial por inovação tecnológica, desemprego, ampliação da economia dos serviços, diminuição da população sindicalizada e enfraquecimento eleitoral dos partidos social-democratas - que poderiam ter afetado de modo irremediável os arranjos dos Estados de bem-estar social.

Nesse ponto, é obrigatório referir a análise de Esping-Andersen (1997), que é menos otimista que os argumentos de Pierson porque assinala a existência de falhas estruturais no Estado de bem-estar social. Primeiro, EspingAndersen identifica a falha do mercado (market failure) afetando o sistema de bem-estar social, isto é, o mau funcionamento do mercado de trabalho no novo contexto da sociedade pósindustrial produz uma sobredemanda nos sistemas de proteção. Segundo, localiza as falhas específicas do arranjo institucional do Estado de bem-estar social (welfare state failure), que foi edificado tendo com referência uma ordem social congelada no tempo, sendo incapaz de

\begin{tabular}{|c|c|c|}
\hline \multicolumn{3}{|c|}{$\begin{array}{l}\text { Percentual médio de gasto social em relação ao PIB de países selecionados } \\
\text { nas décadas de } 1980 \text { e } 1990 .\end{array}$} \\
\hline Países & $1980-1989$ & $1990-1998$ \\
\hline França & 24,33 & 28,47 \\
\hline Alemanha & 20,82 & 25,82 \\
\hline Itália & 20,83 & 24,78 \\
\hline Suécia & 30,06 & 33,52 \\
\hline Reino Unido & 20,20 & 25,00 \\
\hline Estudos Unidos & 13,25 & $14,81^{*}$ \\
\hline
\end{tabular}

* Para os Estados Unidos, os dados se referem ao período de 1990 a 1999.

Fonte: Organização de Cooperação e Desenvolvimento Econômico (OECD), 2002.

responder de modo totalmente adequado aos novos riscos e necessidades colocados pelas mudanças estruturais e demográficas da sociedade contemporânea.

Para Esping-Andersen (1997), os sistemas de bem-estar social foram construídos para atender a uma economia dominada pela produção industrial de massa. Na era do consenso keynesiano, não havia a explicitação do dilema entre seguridade social e crescimento econômico; entre igualdade e eficiência. Nos tempos atuais, esse consenso subjacente não mais existiria: o crescimento não inflacionário por indução da demanda em um único país parece impossível; o pleno emprego teria de ser buscado pelo setor de serviços e não no setor industrial; a estrutura das famílias e o papel do provedor único masculino mudaram; a fecundidade declinou fortemente e os modos de vida tornaram-se crescentemente não padronizados.

Essas mudanças teriam afetado de modo irremediável a inserção das economias nacionais no contexto da globalização dos mercados e, por conseguinte, a capacidade de responder ao problema da eqüidade por meio de políticas públicas universalistas ou pela ampliação da provisão social.

Não há dúvida de que o pessimismo de Esping-Andersen desafia a capacidade da teoria política pensar as novas saídas para os processos estruturais de mudança na ordem capitalista.

O texto de Clayton \& Pontusson (2000) retoma os termos propostos por Esping-Andersen para questionar explicitamente as conclusões de Pierson. Para eles, os efeitos desruptivos das mudanças estruturais do capitalismo contemporâneo diminuíram efetivamente a capacidade do sistema de proteção social de perceber os novos riscos e necessidades da população pobre ou excluída pelos novos processos produtivos. 
Os autores procuram demonstrar que teria um déficit na capacidade da política social compensar as desigualdades geradas pelo mercado em três dos quatro países de referência do texto de Pierson (2000) - Alemanha, Inglaterra e Estados Unidos. Nesses países, os pobres estariam ficando mais pobres apesar dos sistemas de compensação por transferência de renda entre estratos de renda (Tabela 2).

Os autores chamam também a atenção, para o fato de que as transferências de recursos para os pobres cresceram em ritmo menor do que a variação da riqueza nacional medida pelo PIB nos quatros países citados por Pierson (Suécia, Alemanha, Inglaterra e Estados Unidos) (Tabela 3). Esse descompasso estaria associado aos processos restritivos de eleição de beneficiários pelos programas elegíveis por teste de meios, que teriam portanto aumentado a proporção de excluídos.

Essa relação não permite, entretanto, chegar a respostas conclusivas sobre o que teria acontecido com os programas seletivos no contexto do ajuste do Estado de bem-estar social. Teriam eles adotado regras mais estreitas de elegibilidade por força de mudanças estruturais? Implementaram a redução nos benefícios, agravando a situação dos que mais perderam com as mudanças macroeconômicas nos anos 19801990, ou os processos de exclusão social contemporâneos passam ao largo dos desenhos de intervenção social conhecidos? Aqui pode-se voltar a referência à falha do sistema de proteção social, nascido em uma ordem social datada no tempo, que pode ser incapaz de responder com presteza aos novos riscos e necessidades colocados pelas mudanças estruturais e demográficas da sociedade contemporânea. Certamente, o desenvolvimento de estudos de avaliação específicos podem ajudar a ampliar as respostas sobre essas questões.

Esses achados não desqualificam, na essência, a proposta de Pierson: a recuperação da mediação das coalizões políticas nacionais no ambiente de ajuste macroeconômico. A capacidade de mobilização e veto das coalizões de beneficiários foi tomada como a variável crucial da sobrevivência dos Estados de bem-estar social. Ele não responde, de fato, sobre a capacidade dessas coalizões criarem saídas politicamente robustas, que ofereçam um horizonte de sustentabilidade aos arranjos solidários atuais do Estado de bem-estar social frente às mudanças estruturais da economia por força de processos supranacionais. Porém, oferece caminhos muito interessantes para que seja repensada a relação entre a política e a economia.

\section{A agenda social e 0 ajuste macroeconômico no Brasil nas décadas de 1980-1990}

Para o Brasil, é necessário considerar com maior preocupação a hipótese de que a agenda social foi severamente constrangida pelas mudanças nas estratégias de desenvolvimento nacional com o alinhamento à internacionalização da economia na década de 1990. Nesse sentido, parece bastante consistente a tese defendida por Draibe sobre os dois ciclos de reformas das políticas sociais no Brasil: o que ocorreu nos anos 80 , no quadro da instabilidade econômica e da democratização, e o ciclo da segunda metade dos anos 90, pautado pela agenda da estabilização, reformas institucionais e consolidação democrática (Draibe, 2002).

O ponto controverso na formulação da autora é sobre o peso relativo do legado institucional do primeiro ciclo que "constituiria os fatores decisivos de particularização das orientações e conteúdos das reformas recentes dos programas sociais brasileiros" (Draibe, 2002:1). Para ela, existiriam casos de relações tipo path dependency entre os dois ciclos. Seria, no entanto, mais cauteloso considerar que essa relação tenha sido única no campo da saúde, o que torna muito mais complexa a avaliação do significado do segundo ciclo das políticas públicas sociais no Brasil.

Para compreender as mudanças decorrentes das reformas do segundo ciclo, é necessário considerar a hipótese de Haggard \& Kaufman (1992), sobre o estreitamento das opções de políticas públicas de orientação nacional nos anos 1980-1990, principalmente nas economias não desenvolvidas ou dependentes de financiamento externo. É impossível ignorar os efeitos dos novos constrangimentos e condicionalidades macroeconômicas sobre a dinâmica da proteção social no Brasil.

Não há dúvida que a distinção das duas décadas é útil porque, até o começo da década de 1990, as orientações para o ajuste tiveram uma difusão e incorporação residuais sobre as opções econômicas e engenharias institucionais brasileiras. As políticas de ajuste macroeconômico não desempenhavam um papel determinante no encaminhamento das decisões públicas. Esse comportamento brasileiro é explicado pelo fato de que os países ofereceram, na década de 1980, respostas muito diferenciadas às proposições de integração subordinada à globalização.

Haggard \& Kaufman (1992) descrevem quatro fatores que explicariam o comportamento das economias não desenvolvidas: (i) o timing 
para o começo das reformas, que refletiu o grau diferenciado de urgência em responder às iniciativas de estabilização e ajuste; (ii) a capacidade de apoio político das coalizões políticas nacionais às orientações para o ajuste macroeconômico em termos da consolidação e institucionalidade; (iii) a capacidade administrativa dos Estados em políticas específicas, objeto de reformas setoriais e (iv) o tipo de regime político, se democrático ou autoritário, que tenha patrocinado as políticas de estabilização e ajuste. No caso brasileiro, o novo regime democrático, estabelecido em 1985, certamente definiu uma agenda orientada para interesses domésticos que prevaleceu no país até o início da década de 1990.

No contexto da redemocratização dos anos 80 , a economia brasileira resistia ao processo de difusão e aprendizado de orientações normativas do ajuste macroeconômico. As decisões de política econômica respondiam com elevado grau de autonomia aos incentivos e condicionalidades em políticas, definidos pela comunidade financeira internacional. Entre 1979 e 1994 houve nove planos de estabilização, cinco moedas, cinco congelamentos de preços, vinte e duas propostas de renegociação da dívida externa e dezenove modificações nas regras de câmbio.

As várias tentativas de políticas de estabilização e ajuste macroeconômico produziram impactos residuais sobre o sistema de proteção social, e nos indicadores de acesso e utilização de serviços sociais. As tradições organizacionais das políticas setoriais e as exigências do sistema político democrático recém instituído, foram as variáveis institucionais que permitiram ao setor social uma impermeabilidade diante das bruscas alterações de cenários macroeconômicos.

Pode-se verificar que na década de 1980, não houve uma descontinuidade no crescimento da proteção social: foi expandido o gasto público e adotados critérios universalistas para definição de direitos. Esse incremento na incorporação de novas clientelas ao sistema de proteção social foi formalizado na Constituição de 1988.

Com a instituição da estabilização proposta pelo Plano Real, em 1994, pode-se dizer que o conjunto de instrumentos e políticas econômicas de que é dotado o Estado, sofreu uma centralização organizada com o objetivo de estabilizar os gastos públicos, com efeitos importantes sobre a inserção da economia no mercado global. Esse é um ponto muito importante para explicar a dinâmica da proteção social a partir de meados da década de 1990 no Brasil. Tenta-

\begin{tabular}{|c|c|c|}
\hline & $\begin{array}{l}\text { Antes dos impostos } \\
\text { e transferências }\end{array}$ & $\begin{array}{l}\text { Depois dos impostos } \\
\text { e transferências }\end{array}$ \\
\hline \multicolumn{3}{|l|}{ Suécia } \\
\hline 1981 & 16,4 & 6,0 \\
\hline 1992 & 20,6 & 3,8 \\
\hline \multicolumn{3}{|c|}{ Alemanha } \\
\hline 1978 & 13,1 & 2,0 \\
\hline 1989 & 14,1 & 2,4 \\
\hline \multicolumn{3}{|c|}{ Inglaterra } \\
\hline 1979 & 20,0 & 3,1 \\
\hline 1991 & 25,7 & 5,3 \\
\hline \multicolumn{3}{|c|}{ Estados Unidos } \\
\hline 1979 & 18,8 & 10,6 \\
\hline 1991 & 21,0 & 11,7 \\
\hline
\end{tabular}

Fonte: Pierson (2000).

Tabela 3

Média de crescimento anual do gasto social total (a preços constantes), por indivíduo pobre (40\% da renda média) e PIB real per capita, 1979-1992.

\begin{tabular}{lcc}
\hline & Gasto social/pobres & PIB real per capita \\
\hline Suécia 1981-1992 & 0,66 & 1,02 \\
Alemanha 1978-1989 & 0,87 & 2,11 \\
Inglaterra 1979-1981 & 1,63 & 1,87 \\
Estados Unidos 1979-1991 & 0,81 & 1,23
\end{tabular}

Fonte: Pierson (2000).

tivas de planos anteriores esbarraram nesses impasses de ordem política interna, além de inconsistência técnica na confecção dos próprios planos e da falta de condições internacionais que viabilizassem o seu sucesso.

No novo cenário, a formulação sobre a provisão social estará diretamente associada à mudança do modelo de desenvolvimento integrado à globalização da economia. Essas mudanças trariam a significativa diminuição do grau de liberdade das políticas orientadas para dentro (modelo desenvolvimentista), e um maior esforço na busca de legitimação externa para garantir investimentos e créditos.

Para que essa política fosse atraente para os agentes externos, tornou-se necessário iniciativas políticas de austeridade fiscal sobre setor 
público não financeiro, exclusivamente assegurado por superávit primário do conjunto do setor público. Com isso, o país obteve entre 1994 e 2002, um expressivo êxito na estabilização dos gastos públicos para efeito de legitimação da economia brasileira no contexto da globalização financeira (Tabela 4).

Esse novo contrato estabeleceria os limites para as despesas sociais na década, e afetou duramente a capacidade de interferência dos arranjos institucionais da década de 1980 na dinâmica dos programas sociais. O caso da política de saneamento pode ser tomado como um caso exemplar das conseqüências práticas desse constrangimento (Costa, 1995).

Os grandes temas que dominaram a agenda da política pública a partir de então, seriam o incentivo à centralização e insulamento das políticas macroeconômicas, em especial da política monetária, pela autonomia do Banco Central em relação ao Executivo e ao Legislativo; o controle das despesas não financeiras do governo federal; a reforma administrativa do governo federal e governos subnacionais; a privatização das atividades de prestação de serviços públicos; a liberação do comércio externo e outras reformas orientadas para a abertura do mercado interno; e a adoção de políticas focalizadas e de proteção seletiva aos grupos mais vulneráveis aos processos de ajuste no modelo de desenvolvimento.

A agenda de integração intencional à dinâmica da globalização será extremamente bem sucedida na criação de coalizões majoritárias cosmopolitas para a implementação de uma

Tabela 4

Desempenho primário (evolução das receitas e despesas não-financeiras do setor público brasileiro - federal, estadual e municipal - em \% do PIB). Brasil, 1994-2003.

\begin{tabular}{ll}
\hline Ano & Desempenho primário \\
\hline 1994 & 5,04 \\
1995 & 0,36 \\
1996 & $-0,09$ \\
1997 & $-0,91$ \\
1998 & 0,01 \\
1999 & 3,28 \\
2000 & 3,55 \\
2001 & 3,75 \\
2002 & 3,53 (até agosto de 2002) \\
2003 & 3,75 (projeção) \\
\hline
\end{tabular}

Fonte: Banco Central e Jornal Valor (07/10/2002). nova pauta de política macroeconômica. Essa reorientação da política de desenvolvimento aumentou a vulnerabilidade externa da economia nacional, como mostra a evolução expressiva da dívida pública líquida do país entre 1994 e 2002 (Tabela 5), mesmo considerando as receitas extraordinárias advindas do aumento da carga fiscal e das privatizações.

Ao longo da década de 1990, essa agenda será hegemônica na formulação das políticas nacionais e na decisão governamental para as áreas sociais de menor poder de mobilização de interesses e formulação de política, como o saneamento, a habitação e a educação.

Como o modelo de desenvolvimento orientado para dentro não conseguiu oferecer as respostas imediatas para o alívio da dívida social, como prometido no contexto da abertura democrática de meados de 1980, a nova agenda de política pública introduzirá um vasto número de inovações organizacionais no setor social.

Pode-se afirmar que esse novo cenário não permitiu encaminhamento de soluções abrangentes para as políticas sociais, em razão dos pressupostos aceitos para a integração da economia brasileira na globalização. Esses pressupostos levaram negação da agenda universalista em determinadas áreas sociais, a focalização de programas e o constrangimento ao financiamento social.

O documento do governo federal para a área social Uma Estratégia para o Desenvolvimento Social (Presidência da República, 1996), ao enunciar que "o padrão de crescimento de industrialização protegida, conduzido pelo Es-

\begin{tabular}{|c|c|}
\hline \multicolumn{2}{|c|}{$\begin{array}{l}\text { Evolução da dívida pública líquida em relação } \\
\text { ao PIB. Brasil, 1994-2002. }\end{array}$} \\
\hline Ano & $\begin{array}{c}\text { Dívida pública líquida } \\
\text { em \% do PIB }\end{array}$ \\
\hline 1994 & 30,3 \\
\hline 1995 & 30,8 \\
\hline 1996 & 33,2 \\
\hline 1997 & 34,3 \\
\hline 1998 & 41,7 \\
\hline 1999 & 49,3 \\
\hline 2000 & 49,4 \\
\hline 2001 & 53,2 \\
\hline 2002 & 61,9 \\
\hline
\end{tabular}

Fonte: Banco Central e Jornal Valor (04/10/2002). 
tado e baseado na substituição de importações, deixou um complexo sistema de proteção social" que seria parte de "um problema a ser enfrentado pela política social brasileira no futuro próximo" (Presidência da República, 1996:15), definiu uma agenda de fragilização ativa do legado desenvolvimentista-universalista.

O documento sublinhou os aspectos essencialmente regressivos do sistema de proteção social - incorporação progressiva e desigual de corporações profissionais, gastos elevados, centralização administrativa, escasso controle democrático, ineficiência operacional e concentração dos benefícios nos grupos de maior renda - e o considerou como simples expressão de "uma rede complexa de interesses e de direitos adquiridos, envolvendo políticos, funcionários, fornecedores e beneficiários privilegiados" (Presidência da República, 1996:15).

A agenda definiu que a reestruturação desse sistema seria por meio da (i) descentralização, (ii) elevação do controle público, (iii) racionalização dos gastos, (iv) aumento da eficiência alocativa, (v) melhoria de qualidade, (vi) ampliação da cobertura universal e (vii) aumento do impacto redistributivo.

No entanto, essa reestruturação seria subordinada a duas soluções macro políticas cruciais, que neutralizaram os objetivos de eficiência e a preocupação com os mais pobres: (i) a garantia das condições de estabilidade macroeconômica para realizar a reforma do Estado e retomar o crescimento econômico - "sob as novas condições de abertura da economia e elevada competição" (Presidência da República, 1996: 19); (ii) a concentração do esforço e da atenção nos serviços básicos sociais de vocação universal: educação, saúde, previdência social, habitação e saneamento básico, trabalho e assistência social.

“O governo está comprometido com a reestruturação e reforma profunda desses setores com o objetivo de eliminar os desperdícios e aumentar a eficiência desses setores, promover a descentralização, universalizar sempre que necessário e legítimo, sua cobertura e, sobretudo, reestruturar benefícios e serviços para aumentar seu impacto redistributivo" (Presidência da República, 1996:19 - grifos no original).

Parece evidente que a estabilidade econômica com integração externa, ofereceram as condições necessárias e suficientes para a reestruturação do sistema de proteção social pelas restrições impostas à disponibilidade de financiamento do setor público, como mostram as Tabelas 6 e 7 .

As políticas sociais brasileiras foram constrangidas (i) pela estabilização dos recursos em determinadas áreas sociais em patamar extremamente baixos; (ii) pela redução em termos

Tabela 6

Gasto social federal: comparação entre despesa financeira e despesa não-financeira.

\begin{tabular}{lcccccc}
\hline Descrição & 1993 & 1994 & 1995 & 1996 & 1997 & 1998 \\
\hline Gasto social/despesa financeira & 0,57 & 0,59 & 0,70 & 0,67 & 0,46 & 0,36 \\
Gasto social/despesa não-financeira & 0,58 & 0,61 & 0,62 & 0,60 & 0,63 & 0,62 \\
\hline
\end{tabular}

Fonte: IPEA (2000)

Tabela 7

Gasto social federal: comparação com o PIB.

\begin{tabular}{|c|c|c|c|c|c|c|}
\hline Itens & 1993 & 1994 & 1995 & 1996 & 1997 & 1998 \\
\hline PIB total (em R\$ milhões correntes) & 14.097 & 349.205 & 646.192 & 778.820 & 868.159 & 901.898 \\
\hline $\begin{array}{l}\text { Gasto social federal (em } \mathrm{R} \$ \\
\text { milhões correntes) }\end{array}$ & 1.698 & 42.530 & 80.259 & 92.290 & 105.681 & 114.533 \\
\hline $\begin{array}{l}\text { Participações relativas (\%) gasto } \\
\text { social federal/PIB }\end{array}$ & 12,0 & 12,2 & 12,4 & 11,8 & 12,2 & 12,7 \\
\hline
\end{tabular}

Fonte: IPEA (2000). 
absolutos dos gastos sociais em áreas críticas, como assistência social e educação (Tabela 8); (iii) pela oscilação na disponibilidade financeira líquida em áreas estratégicas para o bem-estar social, como no caso da saúde, mostrado por Piola \& Biasoto (2001).

As políticas públicas sociais foram consideradas na década de 1990, um obstáculo à abertura comercial e financeira do país a ser reestruturado por meio de políticas focalizadas e seletivas. Os constrangimentos financeiros que estabilizaram os gastos em patamar crítico, em alguns setores chaves, decorreram da aceitação equivocada da atuação regressiva e da baixa efetividade do sistema de proteção social construído nas décadas passadas. Em decorrência desse diagnóstico, a estabilização macroeconômica afetaria severamente alguns setores, como o saneamento e a habitação, onde é verificável evidências de focalização dos programas sociais na experiência brasileira dos anos 1990.

Nos setores de política social, onde coalizões de interesses tiveram capacidade de mobilização e de acomodação de interesses, como foi o caso da saúde, lembrado por Draibe (2002), a governança setorial teve sucesso na estabilização dos gastos públicos federais, sem alterar os fundamentos da proposta da universalização pela descentralização. Nesse caso, a universalização parecer ter sido mais efetiva em assegurar o acesso dos grupos mais pobres aos benefícios da política de saúde, ainda que mantendo padrões muito elevados de desigualdade entre os estratos renda (IBGE, 2000).
Em resumo, a primeira parte do texto apresenta os argumentos que negam a hipótese do desmantelamento dos sistemas de bem-estar social das economias centrais por falta de evidências de mudanças substanciais nos mecanismos de financiamento e eleição de beneficiários.

Na segunda parte, o texto problematiza sobre os efeitos do processo de internacionalização da economia brasileira no sistema de proteção social do país. Conclui que as restrições impostas aos gastos públicos podem ter limitado severamente a capacidade de promover políticas sociais abrangentes. Verificou-se na década, a opção por políticas sociais focalizadas e seletivas pela adoção do diagnóstico da baixa efetividade do sistema de proteção social brasileiro. O caso da política de saúde foi uma exceção em razão da capacidade de intermediação de interesses na arena setorial.

Nas economias centrais, uma coalizão de partidos social-democratas, burocracia pública e beneficiários enfrentou com sucesso as mudanças brutais na economia globalizada e na capacidade política do "trabalho organizado", neutralizando os ataques conservadores às políticas públicas de natureza redistributiva $\mathrm{e}$ às funções do Estado nacional.

A grande interrogação para o caso brasileiro é saber quais são as possibilidades de fazer esse mesmo caminho, considerando o elevado grau de vulnerabilidade da economia brasileira, aprofundada na década de 1990 pela aceitação do diagnóstico da crise do Estado nacional,

Tabela 8

Gasto social federal per capita por área de atuação (valores em Reais de dezembro/1999).

\begin{tabular}{|c|c|c|c|c|c|c|}
\hline Área de atuação & 1993 & 1994 & 1995 & 1996 & 1997 & 1998 \\
\hline Educação e cultura & 58,3 & 72,8 & 66,9 & 60,1 & 56,4 & 57,1 \\
\hline Saúde & 97,0 & 107,4 & 134,9 & 114,0 & 134,7 & 115,5 \\
\hline Alimentação e nutrição & 3,7 & 6,2 & 4,3 & 7,4 & 6,4 & 8,0 \\
\hline Saneamento e proteção meio ambiente & 6,0 & 3,2 & 1,5 & 5,6 & 6,3 & 5,6 \\
\hline Previdência social & 289,9 & 281,0 & 338,3 & 356,3 & 381,1 & 411,5 \\
\hline Assistência social & 20,4 & 8,8 & 9,9 & 10,2 & 16,8 & 17,7 \\
\hline Emprego e defesa do trabalhador & 20,0 & 18,9 & 28,5 & 32,0 & 32,3 & 39,9 \\
\hline Organização agrária & 3,5 & 4,6 & 10,6 & 9,6 & 11,9 & 12,8 \\
\hline Ciência e tecnologia & 2,3 & 3,0 & 3,0 & 2,7 & 3,2 & 2,0 \\
\hline Habitação e urbanismo & 7,3 & 5,6 & 2,6 & 6,2 & 7,2 & 7,3 \\
\hline Treinamento de recursos humanos & 0,4 & 0,3 & 0,3 & 0,1 & 0,1 & 0,0 \\
\hline Benefícios a servidores & 109,5 & 143,6 & 164,3 & 166,0 & 173,4 & 175,4 \\
\hline Total de gasto social & 618,2 & 655,3 & 765,1 & 770,1 & 829,8 & 852,8 \\
\hline
\end{tabular}

Fonte: IPEA (2000). 
e pela falta de clareza dos grupos de interesses organizados - sindicatos e burocracias públicas - sobre seu papel estratégico na construção das políticas públicas redistributivas.

\section{Referências}

CLAYTON, R. \& PONTUSSON, J., 2000. Welfare state retrenchment revisited. In: The Welfare State: A Reader (C. Pierson \& F. G. Castles, ed.), pp. 320336, Cambridge: Blackwell Publishers.

COSTA, N. R., 1998. Políticas Públicas, Justiça Distributiva e Inovação: Saúde e Saneamento na Agenda Social. São Paulo: Editora Hucitec.

DRAIBE, S., 2002. Brasil - A proteção social após vinte anos de experimentação reformista. In: Taller Inter-Regional Protección Social en una Era Insegura: Un Intercambio Sur-Sur sobre Políticas Sociales Alternativas en Respuesta a la Globalización. Santiago: Programa de las Naciones Unidas para el Desarrollo.

ESPING-ANDERSEN, G., 1997. Welfare States in Transition - National Adaptations in Global Economies. London: Sage Publications.

HAGGARD, S. \& KAUFMAN, R. R., 1992. The Politics of Economic Adjustment. New Jersey: Princeton University Press.
IBGE (Fundação Instituto Brasileiro de Geografia e Estatística), 2000. Acesso e Utilização de Serviços de Saúde 1998. Rio de Janeiro: IBGE.

PIERSON, P., 1995. Dismantling the Welfare State? Reagan, Thatcher and the Politics of Retrenchment. Cambridge: Cambridge University Press.

PIERSON, P., 2000. The new politics of welfare state. In: The Welfare State: A Reader (C. Pierson \& F. G. Castles, ed.), pp. 300-319, Cambridge: Blackwell Publishers.

PIOLA, S. F. \& BIASOTO. G., 2001. Financiamento do SUS nos anos 90. In: Brasil - Radiografia da Saúde (B. Negri \& G. Giovanni, org.), pp. 219-232, São Paulo: Editora Unicamp.

PRESIDÊNCIA DA REPÚBLICA, 1996. Uma Estratégia de Desenvolvimento Social. Brasília: Governo Federal.

Recebido em 15 de maio de 2002

Versão final reapresentada em 16 de outubro de 2002 Aprovado em 21 de outubro de 2002 